\title{
Comparing proportional compositions of geospatial technology-related programs at three universities
}

\author{
Paddington Hodza ${ }^{1}$, Gertrud Schaab ${ }^{2}$, Serena Coetzee ${ }^{3}$, Fritz van der Merwe ${ }^{3}$ and Brandon Vogt ${ }^{4}$ \\ ${ }^{1}$ Wyoming Geographic Information Science Center, University of Wyoming, USA phodza@uwyo.edu \\ ${ }^{2}$ Faculty of Information Management and Media, Karlsruhe University of Applied Sciences, Germany \\ ${ }^{3}$ Centre for Geoinformation Science, Department of Geography, Geoinformatics and Meteorology, University of \\ Pretoria, South Africa \\ ${ }^{4}$ University of Colorado, Colorado Springs, USA
}

DOI: http://dx.doi.org/10.4314/sajg.v4i3.5

\begin{abstract}
Today, graduates seek employment in a global marketplace, regardless of the country in which they studied. Comparing academic programs helps students, academics and employers to make informed decisions about study options, program offerings and the employment of recent graduates. In this study, we juxtapose geospatial technologyrelated programs at three universities located in Europe, Africa and America. Initially, the authors contributed information about these programs through a questionnaire comprising several open-ended questions about the origins and development of the respective programs. Subsequently, the proportional thematic compositions of programs at the three universities were compared. As expected, this study was not without challenges. From the outset, we struggled with agreeing on terminology and semantics. Results of the study indicate that there is not a one-size-fits-all strategy for establishing, shaping and sustaining such programs. Program composition is guided by many factors, including staff expertise, university politics, legislation, attractiveness to students, technological developments, demands in the job market and requirements set by a professional body. Some of these factors are strongly influenced by the local (university) environment (e.g. staff expertise), others are of national relevance (e.g. legislation and a national professional body), while some apply globally (e.g. technological developments). The study illustrated how a comparison of proportional program composition can reveal significant differences and similarities that are not obvious when only content is compared. The compositional differences naturally result in graduates with different knowledge and skills that allow different career paths and meet different needs of the job market.
\end{abstract}

\section{Introduction}

Today, graduates may apply for work in international organizations or in a different country from where they studied. There are many challenges in evaluating and comparing academic course credits, starting with non-uniform descriptions of content. Comparing content descriptions on their own is not always adequate, as the content can be taught at different learning levels. Even if detailed descriptions of content and learning levels are available, these are rarely included on academic transcripts (Coetzee et al. 2015). Comparing academic programs helps students, academics and employers to make informed decisions about study options, program offerings and the employment of recent graduates.

In the USA, creating a model geographic information science and technology (GIS\&T) program in the form of a Body of Knowledge (GIS\&T BoK) has been explored broadly to ensure complete coverage of key geospatial technologies (e.g., DiBiase et al. 2006; Kemp and Goodchild 1991; Kemp et al. 1992) and specifically by considering the needs of individual communities (e.g., Mannel et al. 2007; Benhart 2000; Kostelnick et al. 2009). Furthermore, some authors have looked at developments in technologies to predict what GIS\&T curricula should look like in the future based on past trends (e.g., Nellis 1994; Drummond and French 2008). A recent European project, GI-N2K, revealed limited awareness and use of the GIS\&T BoK by both universities and employers in Europe. In addition, survey respondents noted dozens of topics not included in the first edition of the GIS\&T BoK. The GI-N2K project results also suggest a possible gap between competences required in the workplace and qualifications on offer. These results will inform work on the revision of the GIS\&T BoK in 2016 (Rip et al. 2014). In South Africa, the academic model for geomatics practitioners in the geographic information science (GISc) branch is currently being revised in order to align it with the GIS\&T BoK.

Users and developers of geographic information systems (GIS) draw on many disciplines, including geography, surveying, cartography, computer science, mathematics and physics. Related university programs originated from one or more of these disciplines, resulting in different foci and considerable debate about the appropriate mix of content from these disciplines in a curriculum (Coetzee et al. 2014). A side-by-side analysis of these programs is interesting for many reasons. For students, the comparison can generate insight valuable in making decisions about academic careers. For university educators, such a comparison can inform implementations of similar programs or provide tried-andtested strategies to enhance their own programs. Finally, employers will find value in understanding the differences in composition and shaping of academic programs on offer. 
This paper juxtaposes programs in geomatics, geoinformatics and GIS\&T at three universities located on three continents: the Karlsruhe University of Applied Sciences (HsKA, Germany), the University of Pretoria (UP, South Africa) and the University of Colorado Colorado Springs (UCCS, USA). The universities were selected primarily because the authors of this paper currently work or have at one point worked for these institutions and thus have indepth knowledge of their programs. Insight into the programs was collected from the authors through a questionnaire comprising several open-ended questions on the origins, and development of the programs. This information is included in section 2. In addition, based on a credit-based quantitative description of the composition of each program, the proportional compositions of the programs were compared and analysed. The results are presented in section 3 . A discussion follows in section 4; and concluding comments in section 5.

\section{The origins and development of programs at HsKA, UCCS and UP}

\section{$2.1 \quad$ HsKA}

In 2013, HsKA celebrated two anniversaries: 50 years of a degree program in surveying and 35 years of a degree program in cartography (Freckmann and Saler 2013). The latter was initiated due to a growing demand for cartographic engineers and began with a focus on thematic cartography and cartographic automation. A 1992 study program reform at HsKA allowed students to specialize in either 'cartography' or 'geoinformatics' in their last year of studies (Figure 1). In 1995, legislative changes for so-called universities of applied sciences in the federal state of Baden-Württemberg (into which HsKA falls) called for a restructuring of the curriculum from one with many diverse courses into one with five modules per semester, each with six contact hours per week. This resulted in the renaming of the four-year Diplom degree as 'Cartography and Geomatics' in 1999. (Diplom refers to the name for an academic degree in science and engineering in German-speaking countries and those under the influence of the former Austrian Empire until the introduction of Bachelor and Master degrees due to the Bologna reform. This is not to be confused with Diploma as it is used in the US and South Africa.) The introduction of modules in 1995 greatly facilitated meeting the requirements of the Bologna Declaration of 1999, which sought to harmonize study courses across Europe. As a result, already in 2000 , a Bachelor degree program was introduced in parallel to the Diplom, with many synergies between the two. Only one year later, the International Geomatics Masters was in place. This program was jointly developed by staff involved in the two undergraduate programs, 'Cartography and Geomatics' and 'Surveying and Geomatics', and covered a wide range of topics (Musall 2003, as summarized in Schaab 2014a).

The international Masters program was revised in 2007/8 in response to experience and to new developments in the relevant disciplines. At the same time, recent Bachelor graduates' demand for a consecutive postgraduate offer were accommodated. The now well-tailored program provided students with the option to focus on geomatics and visualization, or on applied geodesy. Immediately after the launch of the revised Masters degree, various reasons (among them the threat to close down the Faculty of Geomatics) led to a new Bachelor study program named 'GeoInformation Management'. This program was jointly developed by all colleagues from the Faculty of Geomatics and started in 2009/10 with three specialization options: Geobusiness, Facilities, and Environment. In addition to the fact that specialization in Facilities did not attract any students, the new program proved to be a direct competitor for beginner students who would have otherwise opted for the cartography program. Consequently, the former degree program in cartography was modified into a 'Cartography and Geomedia' specialization option of the Geo-Information Management Bachelor program. This new option then replaced the Facilities option from 2012/3 onwards. The combined three specialization options experienced a very successful take-off (Schaab 2014a).

In Germany, studies at a university of applied sciences are more application-oriented resulting in a 'job-qualifying' Bachelor degree, while studies at a (fully-fledged) university are known to be more theoretical than applied. At the latter a Bachelor degree is not necessarily meant to be the start of a professional life, but an additional Masters degree which combines taught courses and research is expected (Koch 2013). HsKA's early implementation of the BachelorMaster system set a trend for geospatial technology-related study programs, which other German universities followed. The Bachelor-Master system was seen as a great opportunity for universities of applied sciences, as opposed to the general low opinion of the new system at fully-fledged universities (Schaab 2014b). Furthermore, the Geomatics Masters at HsKA is unique in Germany because it is entirely taught in English. Nowadays, the academic training and education at universities of applied sciences and fully-fledged universities is considered to be on par, resulting in students transferring between the two without any problems and in either direction (Koch 2013). However, one main difference still exists, namely that PhD degrees cannot be awarded by a university of applied sciences, but this is a goal currently being passionately debated (vhw, 2014). 


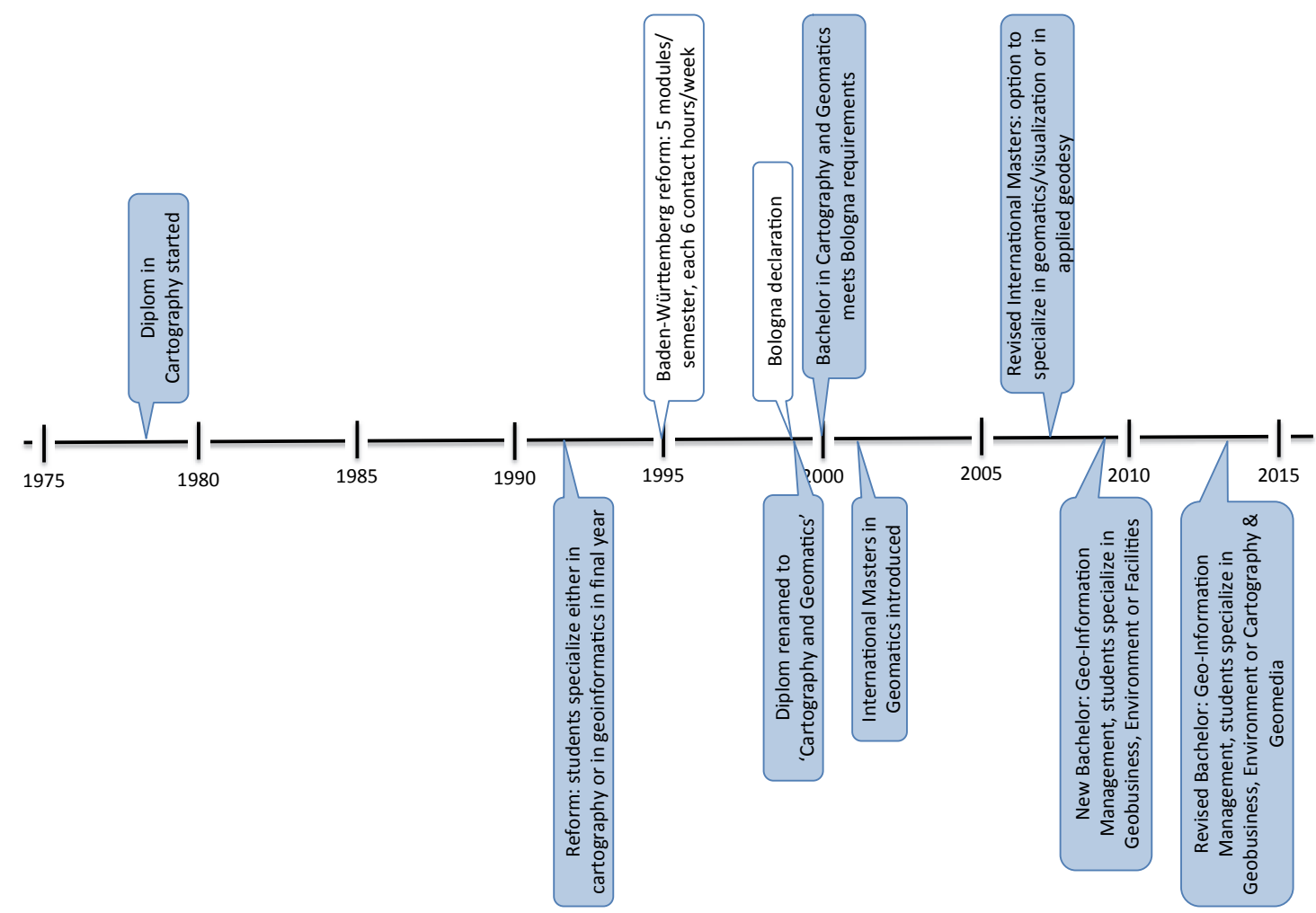

Figure 1. Timeline of major events at HsKA (transparent callouts represent program-external events)

\section{$2.2 \quad \mathrm{UP}$}

Geographic information systems (GIS) arrived in South Africa at a rather late stage. According to Fincham et al. (1993, quoted in MacDevette et al., 2005, p.913), "GIS has a short history in the country, going back no further than the mid 1980s..." (Figure 2). The term was first heard at UP late in 1988 from a surveying software vendor. The reason for the late introduction of GIS can be attributed to the trade sanctions against South Africa during the apartheid regime.

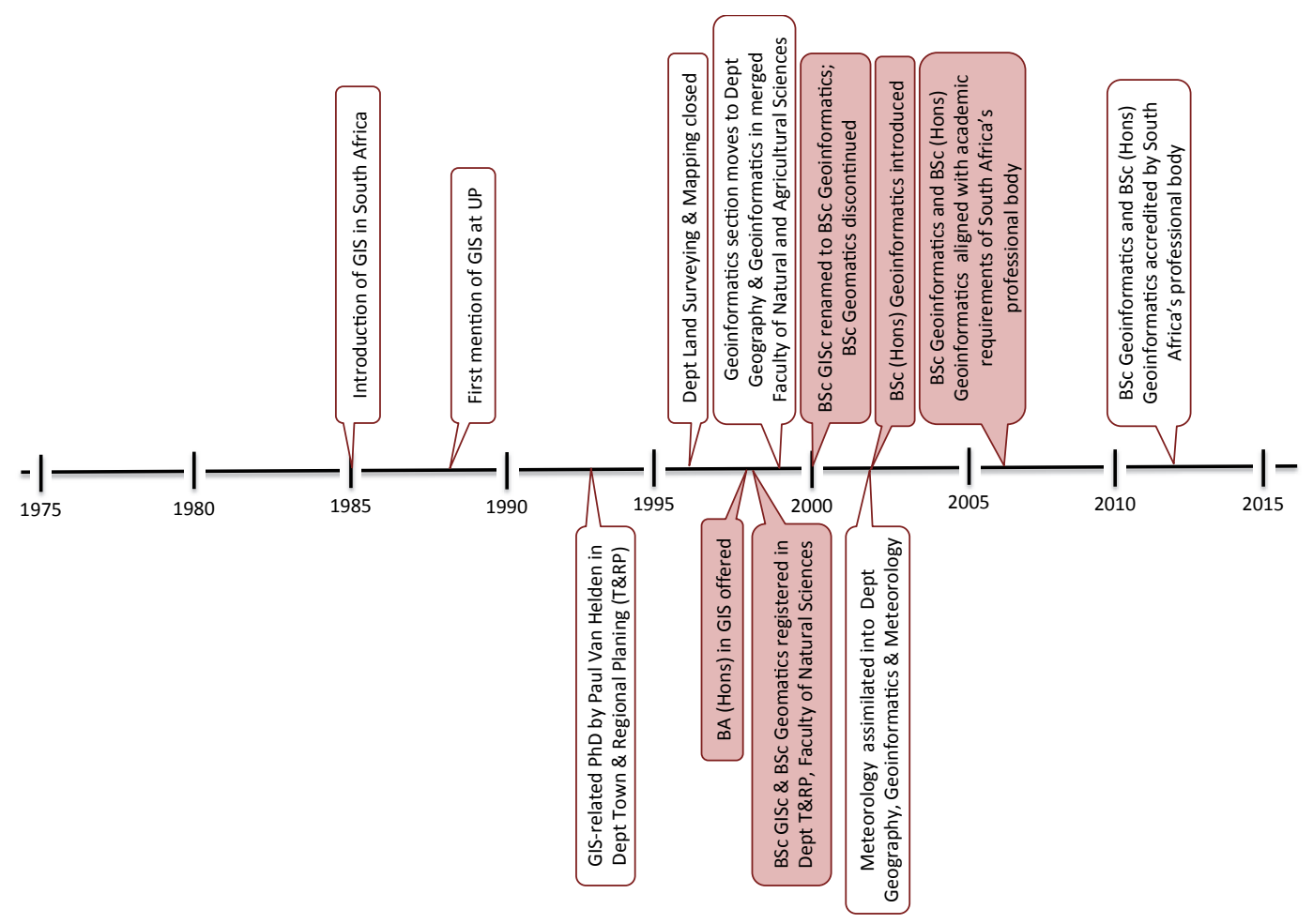

Figure 2. Timeline of major events at UP (transparent callouts represent program-external events) 
In 1993, Paul Van Helden of the Department of Town and Regional Planning (TRP) in the Faculty of Natural Sciences at the UP received his PhD with a dissertation titled 'The Development and Management of an Integrated Information System for Town Planning in a Local Government' (Van Helden, 1993) (translation from Afrikaans). This marked the start of the development of GIS education in the department and formed the basis for future geoinformatics education.

At about the same time, in the private sector, land surveying and town planning practices were competing for contracts to populate and manage land information systems for local governments. The news spread to the Department of Land Surveying and Mapping in the Faculty of Engineering at UP, which started showing an interest in GIS with a desire to incorporate the technology into the curriculum.

In 1996, the university management closed the Department of Land Surveying and Mapping, declaring it financially unsustainable. The staff members were retrenched, except for two, who were left to graduate the last students in the department. These two members, not wanting to be retrenched, combined their expertise in surveying, geodesy and geocomputation and initiated discussions with the Department of Town and Regional Planning; a collaboration started on the development of some form of GIS qualification. After two years of curriculum research and planning and negotiations with the Faculty, the BSc Geographic Information Science and BSc Geomatics degrees were registered in the Faculty of Natural Sciences. The Geomatics degree was discontinued in 2000 due to low student enrolment; at the same time, the other degree was renamed to BSc Geoinformatics.

In 1999, as part of a major restructuring exercise at the university, the Department of Town and Regional Planning was moved to the merged Faculty of Engineering, Built Environment and Information Technology. At the same time, members of the by then geoinformatics section, decided to remain in the merged Faculty of Natural and Agricultural Sciences, and specifically in the Geography department, because geoinformatics is, after all, concerned with geographical information. The department assimilated Meteorology in 2002 and became the department of Geography, Geoinformatics and Meteorology.

Since 1998, a BA (Hons) in Geographic Information Systems was offered, which evolved into the BSc (Hons) Geoinformatics in 2002. In 2006, the BSc Geoinformatics and BSc (Hons) Geoinformatics were aligned to meet the academic requirements of the South African Council for Professional and Technical Surveyors (PLATO). In 2012, the two degrees were accredited by PLATO to meet these requirements. Graduating students now automatically meet the academic requirements for registration as GISc Technologists and GISc Professionals respectively.

\section{$2.3 \quad$ UCCS}

At UCCS, the Department of Geography and Environmental Studies (GES) initially taught its first GIS\&T course, Introduction to Cartography, in 1970 (Figure 3). At that time, the department placed emphasis primarily on physical and human geography. Against this focus, GES slowly introduced additional GIS\&T courses waiting eight years until 1978 to offer the second, Introduction to Remote Sensing. The third and fourth courses, namely Introduction to GIS and Image Processing, an advanced version of the remote sensing course, were only debuted in 1986. Two years later, the department added Advanced GIS to its BA in GES degree curriculum. As GPS became globally available in the mid1990s, and gained widespread use thereafter, GES introduced a GPS with GIS course in 2003 to cover inter alia the powerful linked capabilities of these technologies.

Initially, the courses above were taught by only three GES teaching staff, until two more were hired in 2007. Following the hiring of new staff, GES sought to add and expand geographic information science as another area of departmental emphasis, and conducted a self-assessment of its GIS\&T curriculum (Vogt and Hodza 2013). Generally, UCCS undergraduate courses are offered at 1000, 2000, 3000 and 4000 levels in order of increasing complexity and depth. From its self-assessment, GES realized that save for the 3000-level Introduction to Cartography, all other GIS\&T courses were being taught at the 4000 level. This highest course level created an aura of difficulty that 'scared' GES students, resulting in low enrolments of on average 12 students in GIS\&T courses, while full capacity was 25 students (Vogt and Hodza 2013).

Instead of prioritizing the design of low (1000 or 2000) level courses to immediately address the intimidating nature of high-level GIS\&T courses, an Internet GIS course was developed and taught for the first time in August 2008, then Programming GIS in January 2009. This move expanded the GIS\&T curriculum and brought GES in sync with developments and trends in the field and curricula of GIS\&T. Although this strategy was meant to excite GES students about cutting-edge geospatial technology and thus GIS\&T courses, course enrolment remained about the same. One possible reason is that the students were still required to take only one GIS\&T course; many of which, including the new ones, were still being offered at the 4000 level. 


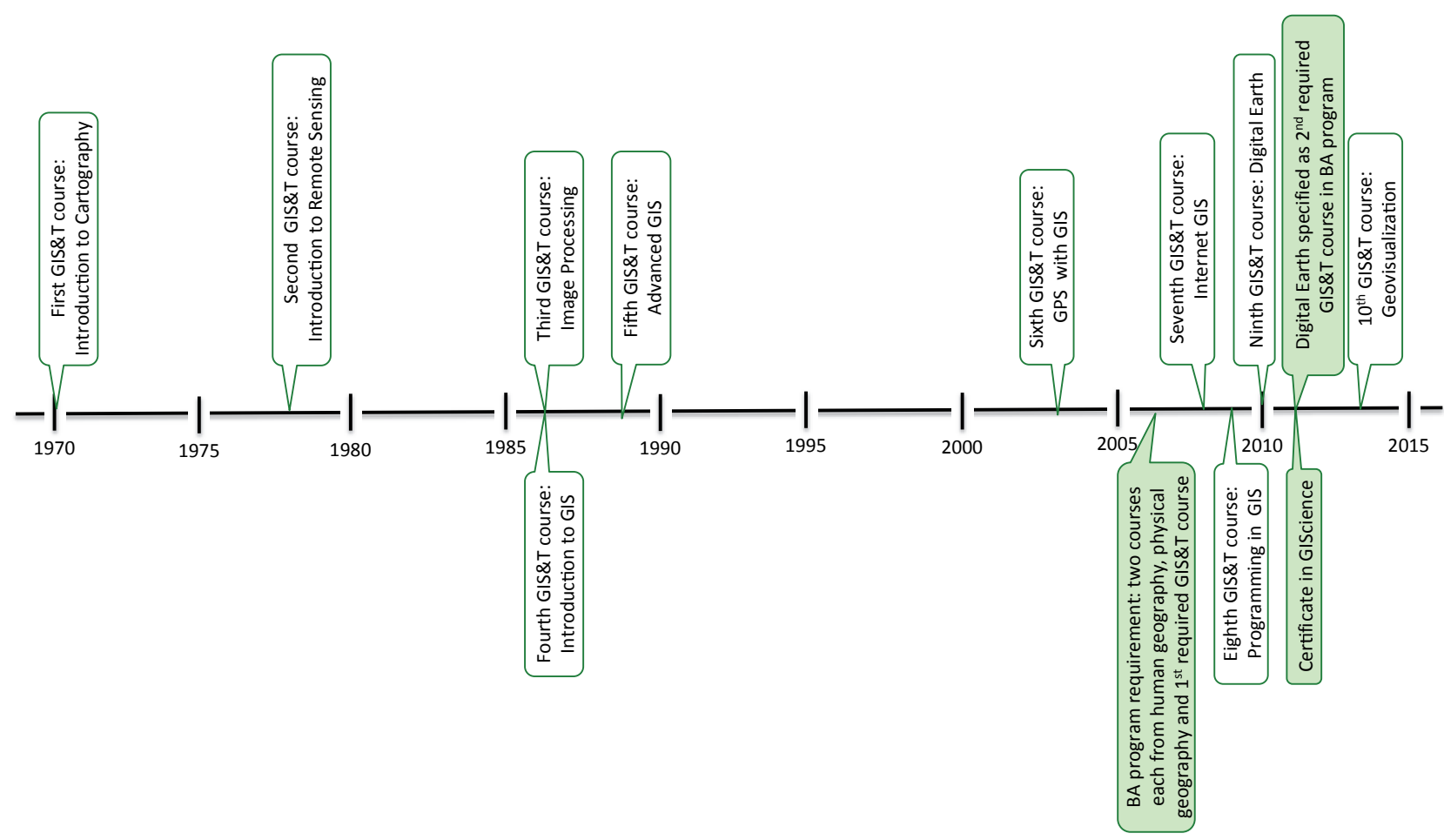

Figure 3. Timeline of major events at UCCS (transparent callouts represent program-external events)

But the above outcome also gave birth to a new 2000-level Digital Earth course as a second required GIS\&T course for all GES students from August 2009 onwards. This course covers the principles, concepts and applications of multiple geospatial technologies. As reported in Vogt and Hodza (2013), its impact was immediate and dramatic. While enrolment in Introduction to GIS, for example, jumped to the full capacity of 25 students in January 2010, the wellestablished physical and human geography areas of focus remained popular and continued to attract relatively more students. Thus, in August 2011, the GES department developed the Certificate in GIScience as an incentive for BA in GES students. The certificate is obtained if a student completes a specified number of GIS\&T courses and it appears on the degree transcript. The certificate is only open to students pursuing an academic degree at UCCS. Since the introduction of the certificate and the Digital Earth course, enrolment has consistently been high in various GIS\&T courses at UCCS.

\section{Comparison of programs at HsKA, UP and UCCS}

\subsection{Method of comparison}

We compared our programs by assigning underlying credits to different themes. Credits are roughly related to contact hours (for lectures, practicals or project work) and strongly related to the time the student is supposed to invest in a given course. Because credit units differ among the universities, only the proportional composition of different themes is considered in the comparison. Geospatial technology is represented by four of these themes, namely cartography/visualization; GIS; surveying/geodata acquisition; and photogrammetry/remote sensing. The subjectspecific 'electives' theme indicates that students may choose the specific geospatial technology-related theme; practical semester work subsumes the listed geospatial technology-related disciplines.

Proportions are slightly different when considering contact hours instead of credits (as performed in Schaab et al. 2014b). One also needs to be aware that a course does not always fit $100 \%$ into one of the themes; some courses are set up to cover several themes. If possible, we opted for the most prominent theme and avoided the splitting of courses among themes.

\subsection{Undergraduate programs}

A first observation can be made on the duration of programs (Figure 4): the BSc programs at UP and HsKA both comprise six semesters of course work; in addition, HsKA students have to complete a practical $\left(5^{\text {th }}\right)$ semester working at an organization. South African graduates who want to register as GISc Technologists with PLATO have to complete 220 days of work integrated learning, but this is not coordinated by the universities. The BA program at UCCS can be completed in eight semesters. Some students choose to take a one semester Professional Experience course involving the application of GIS\&T knowledge and skills in a supervised employment environment. The Certificate in GIScience can be completed in as few as four semesters or as many as eight semesters. 


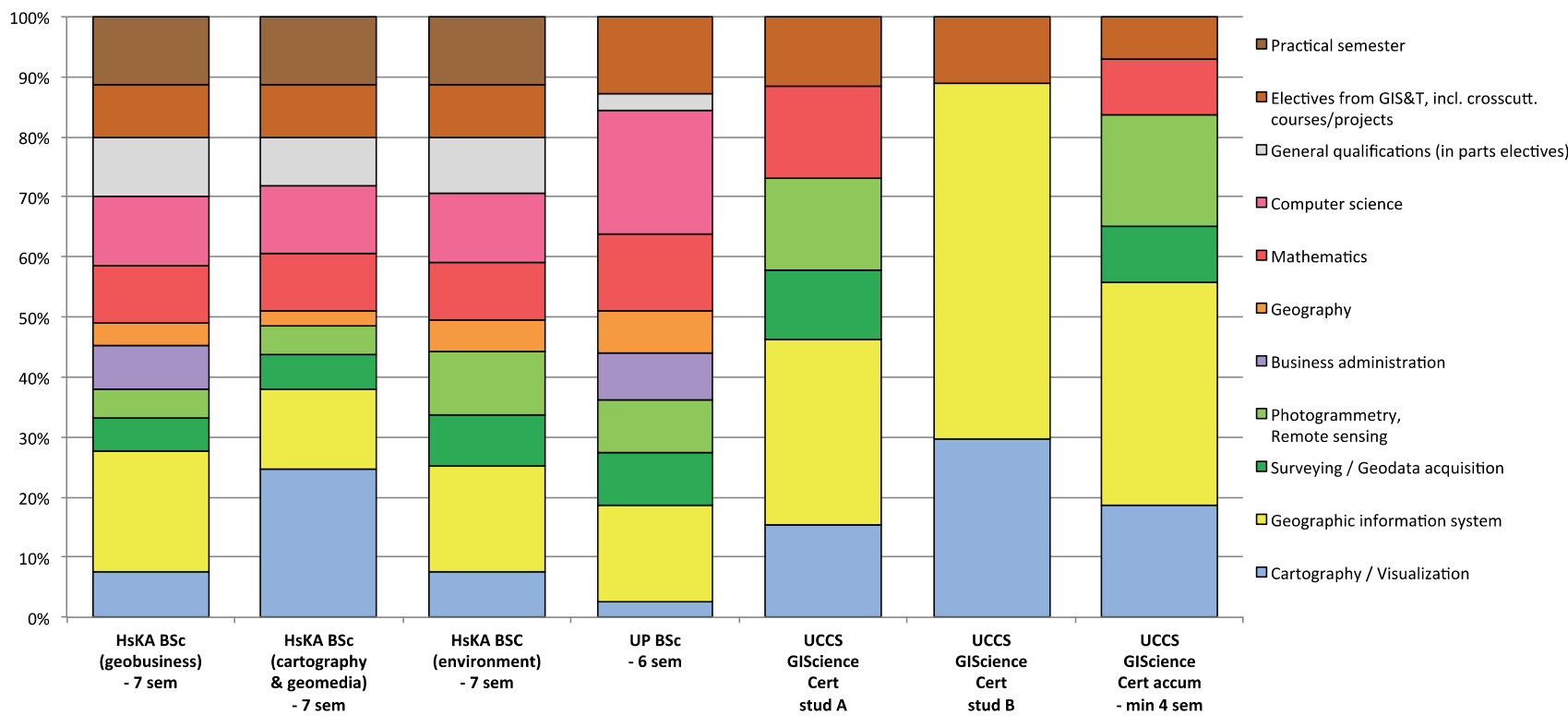

Figure 4. Proportional thematic composition of undergraduate programs at HsKA, UP and UCCS

HsKA's BSc in Geo-Information Management offers three specializations, i.e. students have to choose between Geobusiness, Cartography and Geomedia, and Environment (first three bars in Figure 4). The first two semesters are identical, but from the third semester onwards course content varies increasingly. In the HsKA programs, the basic core disciplines of mathematics and computer science are equally represented ( $10 \%$ and $11 \%$ respectively); the same goes for general qualifications (e.g. languages, soft skills, scientific working), approximately 10\%. Geography content varies $(2 \%$ to $5 \%)$ and it has been questioned whether this small percentage of such a core discipline is sufficient (Schaab 2014b). Approximately $20 \%$ of the program comprises credits earned from 'electives' due to the final Bachelor thesis (comparable to a third year project report in South Africa) and the practical semester; these credits can be in any of the GIS, cartography/visualization, surveying/geodata acquisition or photogrammetry/remote sensing themes.

When following the specialization in Cartography and Geomedia ( $2^{\text {nd }}$ bar in Figure 4$), 25 \%$ of the credits are related to cartography/visualization. This large percentage can be explained against HsKA's background of more than three decades of cartography teaching, initially in the Diplom and later in the Bachelor degree in cartography offered until 2012. GIS courses (13\%) are separate from cartography/ visualization courses at HsKA because visualization and presentation are considered as add-on in GIS courses where the focus is on data editing, analysis and programming.

GIS courses cover $20 \%$ of the specialization option in Geobusiness $\left(1^{\text {st }}\right.$ bar in Figure 4$)$; this includes many geobusiness applications. Courses to gain knowledge in business administration cover 7\% of this specialization. For the two already mentioned specializations, surveying/geodata acquisition and photogrammetry/remote sensing together contribute 11\%; for the third specialization, Environment ( $3^{\text {rd }}$ bar in Figure 4$)$, these courses make up $19 \%$ of the program because geo-monitoring and satellite imagery are more important.

At UP $\left(4^{\text {th }}\right.$ bar in Figure 4$)$ the mathematics and computer science themes amount to $13 \%$ and $21 \%$ of the program respectively. Together with the GIS theme (16\%), this makes up 50\% of the program. Modules in the computer science theme are presented by the Department of Informatics (as opposed to 'pure' computer science). This department focuses on the study of information, information systems and the integration thereof into the organization, for the benefit of the entire system (individual, organization and community) (www.up.ac.za/informatics). A small proportion of cartography/visualization content $(3 \%)$ can be noted, as the application of cartography is generally taught in GIS modules. Surveying/geodata acquisition and photogrammetry/remote sensing are equally represented with $9 \%$; while geography represents $7 \%$ of the course. The UP program allows little flexibility: less than $15 \%$ of the program accounts for subject-specific electives and an elective topic for the third year project.

UCCS differs from both UP and HsKA in that the university offers a Certificate in GIScience, which is embedded within the BA in GES. To obtain the Certificate, a student must complete seven GIS\&T courses: one cross-cutting course, one course in cartography/visualization, two GIS courses and three additional courses from these themes: cartography/visualization (1), geographic information system (2), surveying/geodata acquisition (1), photogrammetry/remote sensing (2) and mathematics (statistical analysis) (1) (www.uccs.edu/geography/baprogram/giscience-certificate.html). Two extremes of several possible course permutations ( $5^{\text {th }}$ and $6^{\text {th }}$ bar), as well as the proportions considering all 11 courses offered $\left(7^{\text {th }}\right.$ bar), are shown in Figure 4. 
The Certificate in GIScience has greater emphasis on the GIS theme, which on average makes up around $40 \%$ of the certificate. Cartography/visualization and photogrammetry/remote sensing provide the same number of course choices, but there is a mandatory requirement for students to take at least one course from the former. The variety in student courses is more apparent at the BA level and also influenced by the liberal studies nature of the educational system (Humphreys and Davenport 2005) at UCCS, which empowers students to decide on which courses to take from a set of allowable courses. Since only two GIS\&T courses are required in the BA in GES (Digital Earth and either Introduction to GIS or Introduction to Remote Sensing), the Certificate in GIScience provides an overlapping scheme, which greatly motivates students to take additional GIS\&T courses.

\subsection{Postgraduate programs}

The MSc in Geoinformatics at UP is research-based, i.e. it does not involve any course work. Admission requirements include a BSc (Hons) Geoinformatics or equivalent degree. While in name, the MSc is similar to the international Masters at HsKA, the course content and set-up of the latter is closer to the BSc (Hons) Geoinformatics at UP. Therefore, the UP Honours program is compared here to the HsKA Masters. UCCS offers an MA in Applied Geography, but it was decided not to include it in the postgraduate comparison because graduate students are not necessarily required to take any GIS\&T courses for the MA in Applied Geography.

Two groups of graduates are admitted to the International Masters in Geomatics at HsKA: 1) students with a Bachelor degree from a German university in a geomatics-affine field (duration 3 semesters; first bar in Figure 5); 2) students from abroad or students with a German Bachelor in e.g., geography, have to enroll in a first so-called 'conversion' semester before continuing with the same three semesters as above (duration 4 semesters; $2^{\text {nd }}$ bar in Figure 5). Tuition fees do not apply, neither for German students nor for students from abroad. The last semester of the Masters at HsKA is dedicated to the Masters thesis (generally called 'dissertation' in South Africa), reflected in the fairly large proportion (39\% and 29\% respectively) in the light brown colour.

During the two course work semesters, the program offers a wide range of electives (see www.hskarlsruhe.de/en/faculties/geomatics/geomatics-international-master/study-programme.html). In Figure 5 electives are presented by likely choices of a student specializing in geomatics and visualization (i.e. a focus on applied geodesy is not included). The differences in proportions between the first two bars are only related to the fixed content of the conversion semester, which ensures that every student has basic knowledge across the full range of the geospatial technology-related themes as well as in programming, statistics/adjustment and the German language (if from abroad).

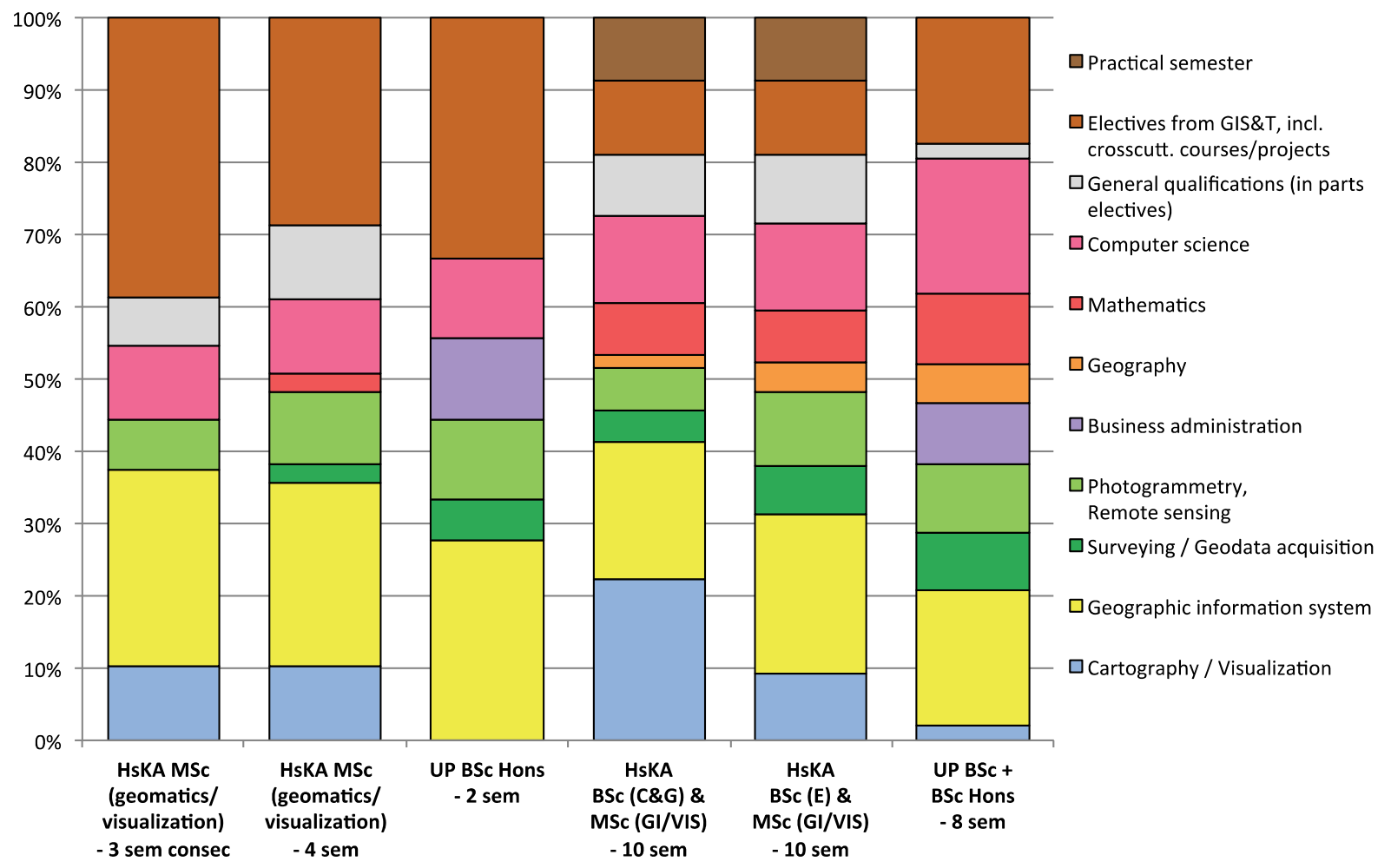

Figure 5. Proportional thematic composition of postgraduate programs at HsKA and UP 
Two groups of students are admitted to the BSc (Hons) Geoinformatics at UP: 1) students with a BSc Geoinformatics or equivalent degree; 2) students with a similar but not equivalent BSc degree may be admitted to a bridging course during which they have to catch up on undergraduate modules, which are presented in day-time only.

The Honours program at UP $\left(3^{\text {rd }}\right.$ bar in Figure 5) shows a third (33\%) of the content not clearly assigned to a theme (in light brown). This is largely due to the research project running over two semesters in which a student may focus on cartography/visualization, GIS, remote sensing/photogrammetry, surveying/geodata acquisition, or a combination of these. Another third of the program (33\%) is evenly split between remote sensing, computer science and business administration (the latter not included in the HsKA Masters). The business administration content comprises professional ethics and South African geomatics related legislation, both required for professional registration with PLATO. The remaining content comprises GIS (28\%) and surveying/geodata acquisition (6\%) content.

The remaining three bars in Figure 5 reveal the proportional composition for the postgraduate options combined with the respective Bachelor programs. The BSc with specialization in geobusiness is not included in Figure 5, as the HsKA Masters program is not considered to be a suitable option for this specialization.

\section{Discussion}

This study set out to investigate the origins, development and proportional thematic compositions of geospatial technology-related programs at three universities. Both UCCS and HsKA started off with courses in cartography. Remote sensing was an early entrant at UCCS; HsKA and UP experienced the same. Initial courses at UCCS were introduced in the second half of the 1980s, but only 20 years later a second push incorporated more GIS\&T courses into the BA program with the latest idea for intensification being the introduction of the Certificate in GIScience in 2011. At that time, the Bachelor programs related to geoinformatics at UP and geomatics at HsKA were already well established.

The study highlighted striking differences and similarities in the driving factors, underlying philosophies and operating environments. The HsKA programs originated in cartography and partially in surveying. They were influenced by developments in geomatics and recently introduced specialization options in geobusiness and environment. UP programs have their origins in cartography, surveying and spatial planning, but ended up as a separate geoinformatics discipline in the Department of Geography, Geoinformatics and Meteorology. In contrast, the UCCS GIS\&T courses are part of a BA program with a strong focus on human and physical geography. Program changes at HsKA were driven by external factors, such as legislation. In addition, major revisions mainly served the purpose of increasing the program's attractiveness for potential students. UCCS steadily introduced new GIS\&T courses in response to technological developments, demand for specific skills from industry and more recently with a desire to increase student numbers and interest in GIS\&T courses. UP initially had frequent program changes when the university restructured, but now changes generally follow the academic requirements by PLATO, the relevant South African professional body. At all three universities, skills and expertise of staff members influence program development and courses on offer.

In Germany, strongly defined academic requirements exist from the professional body representing surveyors. Currently, graduates with a degree in geo-information management are not admitted to a civil service career because they do not have enough credits from surveying and related courses. However, due to an increasing demand for graduates who have specialized in geo-information management and/or geo-information processing, it is expected that these requirements will change in the future. In the US, the GIS Certification Institute (https://www.gisci.org/) offers a voluntary GIS Professional (GISP) certification to individuals who have at least four years of professional GIS experience implying that university graduates would not immediately qualify for this accreditation.

The multidisciplinary nature of GIS is reflected in courses from contributory disciplines included in the undergraduate programs. The GIS theme represents the largest portion in most programs; exceptions are computer science (21\%) in the BSc Geoinformatics at UP and cartography/visualization (25\%) in the Bachelor with specialization in Cartography and Geomedia at HsKA. General themes at UP make up just 3\%, and the 10\% at HsKA appears to be a large proportion in comparison. In Figures 4 and 5 the cartography/visualization courses are strategically positioned at the bottom of each stacked graph because they provide foundational geospatial concepts of revealing and understanding spatial patterns in maps, the most common graphical representations of geospatial information. The visualization/cartography theme is an integral requirement of programs at HsKA and UCCS, and has less emphasis than mathematics at UP.

Apart from GIS, photogrammetry/remote sensing and computer science, the pattern of proportional composition differs significantly for the postgraduate programs at UP (two semesters Honours) and at HsKA (three semesters Masters). Notably, general qualifications and cartography/visualization are not included at UP, while surveying/geodata acquisition and business administration are not included at HsKA when focusing on geomatics and visualization. Both programs have a substantial portion of elective content, 33\% at UP and 39\% at HsKA, representing the Honours report and final Masters thesis respectively. 


\section{Conclusions}

We juxtaposed geomatics, geoinformatics and GIS\&T programs at three universities located in Europe, Africa and America and found that each program has at least one unique feature: the UCCS Certificate in GIScience is embedded in the Bachelor degree; the Bachelor at HsKA includes a practical semester; and the BSc Geoinformatics at UP is accredited by a professional body. While the GIS theme represents the largest portion in most programs, the multidisciplinary nature of GIS is reflected in the inclusion of courses from a considerable number of other themes. There is not a one-size-fits-all strategy for establishing, shaping and sustaining geospatial technology-related programs. The program composition is guided by many factors, including staff expertise, university politics, legislation, attractiveness to students, technological developments, demands in the job market and requirements set by a professional body. Some of these factors are influenced by the local (university) environment (e.g. staff expertise), others by the national environment (e.g. legislation and a national professional body), while some apply globally (e.g. technological developments).

The knowledge and skills required in different application fields vary significantly. By comparing proportional program composition, significant differences and similarities in the programs were revealed that are not obvious when content only is compared. The compositional differences naturally result in graduates with different knowledge and skills that are suitable for significantly different job opportunities and career paths.

As expected, this study was not without challenges. From the outset, we struggled with agreeing on terminology and semantics. While each university produces qualified graduates, there were concerns about juxtaposing programs where students attain significantly different academic credentials; for example, Bachelor degrees vs Certificates (the latter in addition to a BA), and MSc vs BSc Honours. Despite these concerns, we believe that the study was valuable as it illustrated how a comparison of proportional program composition can reveal significant differences and similarities, the findings of which are of immediate relevance to students, academics and employers.

To date, qualitative and quantitative descriptions of the content are typically used to compare study programs. Very often these are based on the 73 units from ten knowledge areas defined in the GIS\&T BoK (DiBiase et al. 2006). While these comparisons are very detailed, they are, in many cases, difficult to digest. Assessing the proportional composition of study programs was first applied by Schaab 2014a/b to compare study course developments over time. In this paper, the approach is applied for the first time to compare study programs at different universities. In future, the approach could be applied to a wider range of study programs related to geospatial technology in order to reveal significant differences and similarities. The approach would also work for a comparison of proportional composition based on the ten knowledge areas (instead of units) defined in the GIS\&T BoK. A totally different approach to the proportional composition comparison would be a more in-depth inspection of course content, learning levels and teaching methods at different universities. However, the significant cost and time effort of such a comparison would require justification.

\section{References}

Benhart, J 2000, 'An approach to teaching applied GIS: Implementation for local organizations', Journal of Geography, vol. 99 , no. 6 , pp. 245-252.

Coetzee, S, Eksteen, S \& Roos, A 2014, 'Results from a survey of the South African GISc community show who they are and what they do', South African Journal of Geomatics, vol. 3, no. 2, pp. 224-245.

Coetzee, S, Rautenbach, V \& Du Plessis, H 2015, ‘A qualitative comparison of South Africa's geomatics professional body's academic model against industry's understanding of SDI knowledge and skills requirements', Journal of Geography in Higher Education, vol. 39, no. 1, pp. 4-17.

DiBiase, DW, DeMers, MN, Johnson, AJ, Kemp, KK, Taylor-Luck, A, Plewe, BS and Wentz EA, 2006, Geographic Information Science and Technology Body of Knowledge, Association of American Geographers, Washington DC.

Drummond, WJ, \& French, SP 2008, 'The future of GIS in planning: Converging technologies and diverging interests', Journal of the American Planning Association, vol. 74, no. 2, pp. 161-173.

Fincham, R, MacDevette, D \& Piper S 1993, International GIS: Southern Africa, International GIS Sourcebook 1993, Fort Collins, GIS World Inc.: pp. 306-308.

Freckmann, P, \& Saler, H 2013, 'Aktueller Stand in den Geomatik-Studiengängen an der Hochschule Karlsruhe Technik und Wirtschaft', Geomatik aktuell 2013 ,,3D-Geodaten” und Jubiläumsveranstaltung: 75 Jahre Vermessung / 35 Jahre Kartographie / 20 Jahre Freundeskreis Geomatik - an der Hochschule Karlsruhe (ed. by K Dürrschnabel et al.), Karlsruher Geowissenschaftliche Schriften, series B, vol. 8, pp. 81-91.

Humphreys, D and Davenport, A 2005, 'What really matters in college: How students view and value liberal education', 
South African Journal of Geomatics, Vol. 4, No. 3, August 2015

Liberal Education, vol. 91, no. 3, pp. 36-43.

Kemp, KK \& Goodchild, MF 1991, 'Developing a curriculum in GIS: The NCGIA Core Curriculum Project', Cartographica, vol. 28, no. 3, pp. 39-54.

Kemp, KK, Goodchild, MF \& Dodson, RF 1992, 'Teaching GIS in geography', Professional Geographer, vol. 44, no. 2, pp. 181-191.

Koch, WG 2013, 'Training Paths in Cartography and Geomatics in Germany, Austria, and Switzerland', Kartographische Nachrichten, Sonderheft/2013, pp. 181-187.

Kostelnick, J, Rowley, R, McDermott, D, and Bowen, C 2009, 'Developing a GIS Program at a Tribal College', Journal of Geography, vol. 108, no. 2.

MacDevette, DR, Fincham, RJ and Forsyth, GG 2005. The rebuilding of a country: the role of GIS in South Africa, in PA Longley, MF Goodchild, DJ Maguire, and DW Rhind (eds.), Geographical Information Systems ( ${ }^{\text {nd }}$ Ed.), John Wiley and Sons, Inc., New York.

Mannel, S, Winkelman, K, Phelps, S \& Fredenberg, M 2007, 'Applications of a GIS program to tribal research: Its benefits, challenges, and extensions to the community', Journal of Geoscience Education, vol. 55, no. 6, pp. 574580.

Musall, H 2003, '25 Jahre Studiengang Kartographie und Geomatik', Entwicklungstendenzen der Kartographie. 25 Jahre Studiengang Kartographie und Geomatik (ed. by C Hermann), Karlsruhe, pp. 3-12.

Nellis, D 1994, 'Technology in Geographic Education: Reflections and Future Directions', Journal of Geography, vol. 93, pp. 36-39.

Rip, F, Wallentin, G \& Van Lammeren R 2014, Integrated analysis of the demand for and supply of geospatial education and training - Results of the GI-N2K Surveys. Lifelong Learning Programme (LLP) - Erasmus Academic Network N ${ }^{\circ}$ 540409-LLP-1-2013-1-BE-ERASMUS-ENW, viewed 1 May 2015, <http://www.gi-

$\underline{\text { n2k.eu/publications/>. }}$.

Schaab, G 2014a, 'Der Wandel in der Kartographie-Ausbildung an der Hochschule Karlsruhe', DGPF Tagungsband 23 / 2014 der Gemeinsamen Tagung 2014 'Geoinformationen öffnen das Tor der Welt' der DGfK, der DGPF, der GfGI und des GiN, 26-28 March 2014, Hamburg (ed. by E Seyfert, E Gulch, C Heipke, J Schiewe \& M Sester), contribution 226 (session S4.4 Aus- und Weiterbildung).

Schaab, G 2014b, '35 Jahre Kartographie-Ausbildung an der Hochschule Karlsruhe - den Wandel visualisieren', Kartographische Nachrichten, vol. 4, pp. 187-198.

Van Helden, P 1993, Die ontwikkeling en bestuur van 'n geïntegreerde inligtingstelsel vir stadsbeplanning in 'n plaaslike bestuur, $\mathrm{PhD}$ thesis, University of Pretoria, South Africa.

vhw, Verband Hochschule und Wissenschaft (ed) 2014, vhw Mitteilungen. Informationen und Meinungen aus der Hochschulpolitik, vol. 1, pp. 12-20.

Vogt, B \& Hodza, P 2013, 'Using 'Digital Earth' to expose students to GIScience', Journal of Geography, vol. 12, no. 5, pp. 205-213. 